\title{
Socio-economic deprivation and cancer incidence in England: Quantifying the role of smoking
}

3

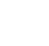

5

6

7

8

9
Nick W. S. Payne ${ }^{1 *}$, Katrina F. Brown ${ }^{1}$, Christine Delon ${ }^{1}$, Yannis Kotrotsios ${ }^{1}$, Isabelle Soerjomataram $^{2}$, Jon Shelton ${ }^{1}$

21 Policy, Information and Communication Directorate, Cancer Research UK, 2 Redman Place,

London, E20 1JQ 


\section{Abstract}

\section{Background}

34 More deprived populations typically experience higher cancer incidence rates and smoking

35 prevalence compared to less deprived populations. We calculated the proportion of cancer

36 cases attributable to smoking by socio-economic deprivation in England and estimated the

37 impact smoking has on the deprivation gap for cancer incidence.

\section{Methods}

Data for cancer incidence (2013-2017), smoking prevalence (2003-2007) and population

40 estimates (2013-2017) were split by sex, age-group and deprivation quintile. Relative risk

41 estimates from meta-analyses were used to estimate the population attributable fraction

42 (PAF) for 15 cancer types associated with smoking. The deprivation gap was calculated using

43 age-specific incidence rates by deprivation quintile.

\section{$44 \quad$ Results}

45 Smoking-related cancer PAFs in England are 2.2 times larger in the most deprived quintile

46 compared to the least deprived quintile (from $9.7 \%$ to $21.1 \%$ ). If everyone had the same

47 smoking prevalence as the least deprived quintile, $20 \%$ of the deprivation gap in cancer

48 incidence could have been prevented. If nobody smoked, $61 \%$ of the deprivation gap could

49 have been prevented.

\section{Conclusions}

51 The majority of the deprivation gap in cancer incidence could have been prevented in

52 England between 2013-2017 if nobody had smoked. Policy makers should ensure that

53 tobacco control policies reduce overall smoking prevalence by tackling smoking inequalities. 


\section{Background}

56 Smoking is the main cause of preventable cancer and death in the UK. ${ }^{1,2}$ In England, smoking

57 accounted for $15 \%$ (around 44,000 cases) of all cancer cases in $2015 .{ }^{1}$ Smoking causes at

58 least 15 different types of cancer, and the proportion of cases caused by smoking varies

59 greatly by cancer type, ranging from $0.3 \%$ for ovarian cancer to $72 \%$ for lung cancer in

60 England.

61 Cancer incidence varies by socio-economic position across the UK. ${ }^{3,4,5,6}$ For example, cancer

62 incidence rates for all cancers combined in England are 17\% higher in the most deprived

63 quintile compared to the least. ${ }^{7}$

64 The majority of cancer types' incidence rates are positively associated with deprivation in

65 England, leading to an estimated 27,200 deprivation-associated cancer cases each year. ${ }^{3}$

66 Many of the cancer types associated with deprivation are also associated with smoking. ${ }^{3,8}$

67 A clear socio-economic divide is observed for adult smoking prevalence in the UK. ${ }^{9}$ In

68 England, smoking prevalence is around 2.5 times higher in the most deprived group

69 compared to the least deprived group. ${ }^{9,10}$ In line with this, previous studies in France and

70 Australia have reported that more deprived populations had a higher burden of cancer

71 incidence attributable to smoking. ${ }^{11,12}$ These studies also investigated the impact of the

72 removal of smoking inequalities, which estimated that $7-13 \%$ of all cancers caused by

73 smoking in men and 8-9\% in women, could be prevented if everyone smoked like the least

74 deprived quintile.

75 We aimed to estimate the proportion of cancer cases attributable to smoking by socio-

76 economic position in England. Additionally, we estimated what proportion of the observed

77 deprivation gap in cancer incidence in England could have been prevented if: 1) everyone had

78 the same smoking prevalence as the least deprived group; 2) nobody smoked. 


\section{Methods}

\section{Cancer Types}

81 To calculate the proportion of cancer cases attributable to smoking we included 15 cancer

82 types which have 'sufficient' evidence of a causal association with smoking based on the

83 International Agency for Research on Cancer (IARC) Monograph ${ }^{8}$ : oral cavity, pharynx,

84 nasopharynx, larynx, oesophagus, stomach, colorectal, liver, pancreas, lung, cervix uteri,

85 kidney, bladder, ovarian (mucinous) and acute myeloid leukaemia (see Supplementary

86 Material A for International Classification of Diseases version 10 codes). These cancers

87 contribute to $44 \%$ (around 134,300 cases) of the total cancer incidence in England every year

88 (2013-2017). We will refer to these cancer types as 'smoking-related cancers'.

89 Only cancer types positively associated with deprivation - defined as having significantly

90 higher age-standardised incidence rates in the most deprived quintile compared to the least

91 deprived - between 2013 and 2017 in England were included for calculation of the observed

92 deprivation gap in cancer incidence ${ }^{3}$ : head and neck (oral cavity, salivary glands, pharynx,

93 nasopharynx, larynx, nasal cavity and middle ear, accessory sinuses), oesophagus, stomach,

94 colorectal, liver, pancreas, lung, cervix uteri, kidney, bladder, small intestine, anal,

95 gallbladder, vulva, vagina, uterus, penis, Hodgkin lymphoma and cancer of unknown primary

96 (see Supplementary Material A for ICD-10 codes). These cancers contribute to 50\% (around

97154,000 cases) of the total cancer incidence in England every year (2013-2017). We will refer

98 to these cancer types as 'deprivation-related cancer types'.

\section{Data sources}

100 Cancer incidence for England between 2013 and 2017 was provided by Public Health

101 England and population estimates between 2013 and 2017 were provided by the Office for

102 National Statistics. Each data set was split by sex, 5-year age band and quintiles of the 
Income domain from the Index of Multiple Deprivation 2015 (IMD 2015). The Income domain of the IMD is a relative, local-level measure of deprivation based on the proportion of the population in that area estimated to experience deprivation because of low income. The cancer data was additionally split by ICD-10 3-digit code, or International Classification of Diseases for Oncology version 3 (ICD-O-3) code (e.g. mucinous ovarian, oesophageal adenocarcinoma and oesophageal squamous cell carcinoma).

Adult (16+ years) smoking prevalence between 2003-2007 and second-hand smoking prevalence was collated from Health Survey for England (HSE) datasets (2003-2007) and categorised by sex, 10-year age band and equivalised household income quintiles, accessed through the UK Data Service. A 10-year latency period between smoking exposure and subsequent cancer incidence was used in line with previous methodology. ${ }^{1,13}$ Smoking prevalence for 2004 had to be imputed using a simple linear model based on available years: 2003, 2005, 2006 and 2007.

Relative risk (RR) estimates (see Supplementary Material A) were obtained from metaanalyses through a literature search using previously defined search terms (see Supplementary Material B). ${ }^{1}$ The literature was reviewed between two researchers (NP and $\mathrm{KB})$ to decide on the most appropriate RR estimate to use for each cancer type.

\section{Population Attributable Fraction formula}

To calculate the proportion of cancer cases attributable to smoking by deprivation quintile, the standard population attributable fraction (PAF) formula was used: ${ }^{13}$

$$
\left(\mathrm{p}_{1} \times \mathrm{ERR}_{1}\right)+\left(\mathrm{p}_{2} \times \mathrm{ERR}_{2}\right)
$$




$$
1+\left[\left(\mathrm{p}_{1} \times \mathrm{ERR}_{1}\right)+\left(\mathrm{p}_{2} \times \mathrm{ERR}_{2}\right)\right]
$$

128 Where $\mathrm{p}_{1}$ is the proportion of 'current cigarette smokers' in England, $\mathrm{p}_{2}$ is the proportion of

129 'ex-regular cigarette smokers', $\mathrm{ERR}_{1}$ is the excess relative risk (relative risk - 1 ) for current

130 smokers and $\mathrm{ERR}_{2}$ is the excess relative risk (relative risk -1 ) for ex-smokers. Lung cancer

131 had a specific adjustment to the calculation which included an extension of the formula above

132 to account for second-hand smoke exposure prevalence (see Supplementary Material C).

133 Smoking-attributable cases were calculated for each cancer type and then summed to obtain

134 figures for all smoking-related cancer types combined. Overall PAF estimates used the

135 smoking-attributable cancer cases as the numerator and all cancers combined excluding non-

136 melanoma skin cancer (C00-C97 excl. C44) as the denominator, by sex and deprivation

137 quintile. PAF estimates are presented for all ages combined (0-99+ years) and broken down

138 by two broad age groups (24-64 years and 65+ years). Confidence intervals were not

139 calculated, all comparisons are based on point estimates.

140 Observed deprivation gap in cancer incidence and smoking

141 To further investigate the contribution of smoking to cancer incidence by socio-economic

142 position in England, we grouped smoking-related cancer types together to form a combined

143 age-standardised incidence rate (ASR) by deprivation quintile (2013-2017). We then

144 modelled ASR's for two hypothetical smoking scenarios based on smoking-related cancer

145 types where: scenario 1) everyone had the same smoking prevalence as the least deprived

146 quintile; scenario 2) nobody smoked. Rates were age-standardised to the 2013 European

147 Standard Population. ${ }^{14}$

148 To calculate the proportion of avoidable cases under each smoking scenario, we used

149 deprivation-associated cases for deprivation-related cancer types (representing the observed 
deprivation gap in cancer incidence) as the denominator, and the number of deprivationassociated cases in scenario 1 and scenario 2 as the numerator.

Deprivation-associated cases were calculated using age-specific incidence rates, as has been

153 previously described. ${ }^{15}$ Briefly, 'expected' cases were estimated by applying the age-specific

154 incidence rate from the least deprived quintile to each population of the remaining 4 quintiles.

155 The 'expected' cases were then subtracted from their corresponding observed cases to

156 produce excess deprivation-associated cases. For the remainder of this article, 'deprivation-

157 associated cases' will be used to refer to excess cases due to higher incidence rates in more

158 deprived populations compared to the least deprived.

159 Confidence intervals were calculated for ASRs, but not for deprivation-associated case estimates. See Supplementary Materials D and E for more detailed information on these calculations.

\section{Sensitivity analysis}

Due to lack of data, the measure of deprivation used for smoking prevalence (equivalised household income) and cancer incidence (income domain of IMD) was not a direct match. To assess the robustness of the main results to differences in deprivation measurement, PAFs were also calculated with smoking prevalence by 'all domains' IMD (7 domains: income, 


\section{Results}

\section{Population Attributable Fraction (PAF) of cancer related to smoking by deprivation}

175 quintile

176 A strong deprivation gradient was observed for the proportion of cancer cases attributable to

177 smoking in England (Table 1). For all ages combined, the smoking PAF was 2.2 times larger

178 in the most deprived quintile compared to the least deprived quintile. The smoking PAF

179 increased from $9.7 \%$ in the least deprived quintile to $21.1 \%$ in the most deprived quintile.

180 Similar relative increases in PAFs were observed for both sexes, but the PAFs were generally

181 larger for males compared to females.

182 A similar deprivation gradient was found for each broad age group. However, the smoking

183 PAFs were generally smaller in the younger age group compared to the older age group.

184 There was variation in PAFs by cancer type, with both lung cancer and laryngeal cancer

185 having the largest PAFs, as well as strong deprivation gradients (Figures $1 \mathrm{a}$ and $1 \mathrm{~b}$ ). 
medRxiv preprint doi: https://doi.org/10.1101/2022.02.11.22270853; this version posted February 13, 2022. The copyright holder for this preprint (which was not certified by peer review) is the author/funder, who has granted medRxiv a license to display the preprint in perpetuity.

All rights reserved. No reuse allowed without permission.

195 Table 1. Average number and proportion of smoking-attributable cancer cases per year by sex, 196 age and deprivation quintile, England, 2013-2017

\begin{tabular}{|c|c|c|c|c|c|c|c|c|c|}
\hline \multirow{2}{*}{$\begin{array}{c}\text { Deprivation } \\
\text { quintile }\end{array}$} & \multicolumn{3}{|c|}{ 25-64 years } & \multicolumn{3}{|c|}{$65+$ years } & \multicolumn{3}{|c|}{ All ages $(0-99+$ years $)$} \\
\hline & $\begin{array}{l}\text { Observed } \\
\text { cases }\end{array}$ & PAF* & $\begin{array}{c}\text { Smoking } \\
\text { attributable } \\
\text { cases }\end{array}$ & $\begin{array}{l}\text { Observed } \\
\text { cases }\end{array}$ & PAF* & $\begin{array}{c}\text { Smoking } \\
\text { attributable } \\
\text { cases }\end{array}$ & $\begin{array}{l}\text { Observed } \\
\text { cases }\end{array}$ & PAF* & $\begin{array}{c}\text { Smoking } \\
\text { attributable } \\
\text { cases }\end{array}$ \\
\hline \multicolumn{10}{|l|}{ Females } \\
\hline 1 (least) & 11,675 & $4.6 \%$ & 542 & 18,654 & $9.7 \%$ & 1,817 & 30,626 & $7.7 \%$ & 2,359 \\
\hline 2 & 11,919 & $6.3 \%$ & 751 & 19,969 & $10.9 \%$ & 2,184 & 32,176 & $9.1 \%$ & 2,935 \\
\hline 3 & 11,404 & $8.2 \%$ & 930 & 18,934 & $13.1 \%$ & 2,482 & 30,654 & $11.1 \%$ & 3,413 \\
\hline 4 & 11,202 & $10.3 \%$ & 1,153 & 17,042 & $16.9 \%$ & 2,872 & 28,569 & $14.1 \%$ & 4,026 \\
\hline 5 (most) & 10,990 & $14.3 \%$ & 1,566 & 15,009 & $19.9 \%$ & 2,991 & 26,398 & $17.3 \%$ & 4,558 \\
\hline \multicolumn{10}{|l|}{ Males } \\
\hline 1 (least) & 8,832 & $9.2 \%$ & 810 & 24,049 & $12.6 \%$ & 3,031 & 33,203 & $11.6 \%$ & 3,841 \\
\hline 2 & 9,067 & $12.1 \%$ & 1,099 & 25,223 & $15.1 \%$ & 3,812 & 34,616 & $14.2 \%$ & 4,911 \\
\hline 3 & 8,954 & $14.9 \%$ & 1,332 & 22,743 & $17.5 \%$ & 3,979 & 32,011 & $16.6 \%$ & 5,311 \\
\hline 4 & 8,945 & $18.1 \%$ & 1,619 & 19,768 & $21.4 \%$ & 4,227 & 29,059 & $20.1 \%$ & 5,846 \\
\hline 5 (most) & 9,228 & $23.4 \%$ & 2,161 & 17,198 & $26.3 \%$ & 4,529 & 26,829 & $24.9 \%$ & 6,690 \\
\hline \multicolumn{10}{|l|}{ Persons } \\
\hline 1 (least) & 20,507 & $6.6 \%$ & 1,352 & 42,703 & $11.4 \%$ & 4,848 & 63,828 & $9.7 \%$ & 6,200 \\
\hline 2 & 20,986 & $8.8 \%$ & 1,850 & 45,192 & $13.3 \%$ & 5,996 & 66,792 & $11.7 \%$ & 7,846 \\
\hline 3 & 20,358 & $11.1 \%$ & 2,262 & 41,677 & $15.5 \%$ & 6,461 & 62,665 & $13.9 \%$ & 8,724 \\
\hline 4 & 20,147 & $13.8 \%$ & 2,772 & 36,810 & $19.3 \%$ & 7,099 & 57,628 & $17.1 \%$ & 9,871 \\
\hline 5 (most) & 20,217 & $18.4 \%$ & 3,727 & 32,206 & $23.3 \%$ & 7,520 & 53,227 & $21.1 \%$ & 11,247 \\
\hline
\end{tabular}

197 *PAF: Population attributable fraction out of all cancers (excl. non-melanoma skin cancer)

198

199 Figures 1a (females) and 1b (males). Population Attributable Fraction (PAF) for smoking, by 200 cancer type and deprivation quintile, England, 2013-2017

201 *Acute myeloid leukaemia; **Oesophageal adenocarcinoma; ***Oesophageal squamous cell

202 carcinoma

203

204 Cancer incidence by deprivation quintile

205 Age-standardised incidence rates by deprivation quintile and sex are displayed in Figures 2a

206 and 2b. A clear deprivation gradient is observed for smoking-related cancer types for both

207 sexes, with a $63 \%$ and a $60 \%$ relative increase in ASR between the least and most deprived

208 quintiles for females and males, respectively.

209 The deprivation gap for incidence rates between the least and most deprived quintiles is

210 partly reduced in scenario 1 to a $51 \%$ and $45 \%$ relative increase in ASR between the least and 
medRxiv preprint doi: https://doi.org/10.1101/2022.02.11.22270853; this version posted February 13, 2022. The copyright holder for this preprint

(which was not certified by peer review) is the author/funder, who has granted medRxiv a license to display the preprint in perpetuity.

All rights reserved. No reuse allowed without permission.

most deprived quintile for females and males, respectively. For scenario 2 where nobody smoked, there is a marked reduction in both the cancer incidence rate and the deprivation gradient, which shows a $28 \%$ and $24 \%$ relative increase in ASR between the least and most deprived quintile for females and males, respectively.

Figures 2a (females) and 2b (males). Combined European Age-Standardised incidence rates (ASR) per 100,000 population for smoking-related cancer types* by deprivation quintile and sex, for observed cancer incidence (the current situation), scenario 1 and scenario 2, England, 2013-2017

*oral cavity, pharynx, nasopharynx, larynx, oesophagus, stomach, colorectal, liver, pancreas, lung, cervix uteri, kidney, bladder, ovarian (mucinous) and leukaemia (acute myeloid)

\section{Deprivation gap in cancer incidence and smoking}

A summary of deprivation-associated cases and the proportion of the observed deprivation gap in cancer incidence that could have been prevented in scenarios 1 and 2 is presented in Table 2. For deprivation-related cancer types, it is estimated that there were an average of 27,156 cases (11,851 in females and 15,305 in males) associated with deprivation every year in England between 2013 and 2017.

If everyone had the same smoking prevalence as the least deprived quintile $20.3 \%(5,504$ cases every year) of deprivation-associated cases could have been prevented. If nobody smoked, $60.9 \%$ (16,544 cases every year) of deprivation-associated cases could have been prevented. 
medRxiv preprint doi: https://doi.org/10.1101/2022.02.11.22270853; this version posted February 13, 2022. The copyright holder for this preprint (which was not certified by peer review) is the author/funder, who has granted medRxiv a license to display the preprint in perpetuity.

All rights reserved. No reuse allowed without permission.

237 Table 2. Estimated average number of deprivation-associated cases per year for deprivation238 related cancer types* and smoking-related cancer types**, scenario 1 and scenario 2; and the 239 estimated number of deprivation-associated cases and proportion of the observed deprivation 240 gap in cancer incidence that could have been prevented, in England, in 2013-2017

\begin{tabular}{|c|c|c|c|c|c|c|c|c|c|c|}
\hline & & \multicolumn{3}{|c|}{ 25-64 years } & \multicolumn{3}{|c|}{$65+$ years } & \multicolumn{3}{|c|}{$\begin{array}{c}\text { All ages } \\
(0-99+\text { years })\end{array}$} \\
\hline & & Female & Male & Persons & Female & Male & Persons & Female & Male & Persons \\
\hline \multirow{4}{*}{$\begin{array}{c}\text { Deprivation- } \\
\text { associated cases }\end{array}$} & $\begin{array}{l}\text { Deprivation - } \\
\text { related cancer } \\
\text { types }\end{array}$ & 4,380 & 5,242 & 9,622 & 7,467 & 10,043 & 17,510 & 11,851 & 15,305 & 27,156 \\
\hline & $\begin{array}{l}\text { Smoking-related } \\
\text { cancer types }\end{array}$ & 3,562 & 4,782 & 8,344 & 6,413 & 9,248 & 15,661 & 10,009 & 14,057 & 24,066 \\
\hline & Scenario $1^{1}$ & 2,605 & 3,481 & 6,086 & 5,403 & 7,012 & 12,415 & 8,043 & 10,519 & 18,562 \\
\hline & Scenario $2^{2}$ & 1,154 & 1,474 & 2,628 & 2,281 & 2,552 & 4,833 & 3,470 & 4,052 & 7,522 \\
\hline \multirow{2}{*}{$\begin{array}{c}\text { Preventable } \\
\text { deprivation- } \\
\text { associated cases } \\
\text { (Preventable } \\
\text { proportion of the } \\
\text { observed } \\
\text { deprivation gap } \\
\text { in cancer } \\
\text { incidence) }^{\mathrm{a}}\end{array}$} & Scenario $1^{1}$ & $\begin{array}{c}957 \\
(21.9 \%)\end{array}$ & $\begin{array}{c}1,301 \\
(24.8 \%)\end{array}$ & $\begin{array}{c}2,258 \\
(23.5 \%)\end{array}$ & $\begin{array}{c}1,010 \\
(13.5 \%)\end{array}$ & $\begin{array}{c}2,236 \\
(22.3 \%)\end{array}$ & $\begin{array}{c}3246 \\
(18.5 \%)\end{array}$ & $\begin{array}{c}1,966 \\
(16.6 \%)\end{array}$ & $\begin{array}{c}3,538 \\
(23.1 \%)\end{array}$ & $\begin{array}{c}5,504 \\
(20.3 \%)\end{array}$ \\
\hline & Scenario $2^{2}$ & $\begin{array}{c}2,408 \\
(55.0 \%)\end{array}$ & $\begin{array}{c}3,308 \\
(63.1 \%)\end{array}$ & $\begin{array}{c}5,716 \\
(59.4 \%)\end{array}$ & $\begin{array}{l}4.132 \\
(55.3 \%)\end{array}$ & $\begin{array}{c}6,696 \\
(66.7 \%)\end{array}$ & $\begin{array}{l}10,828 \\
(61.8 \%)\end{array}$ & $\begin{array}{c}6,539 \\
(55.2 \%)\end{array}$ & $\begin{array}{l}10,005 \\
(65.4 \%)\end{array}$ & $\begin{array}{l}16,544 \\
(60.9 \%)\end{array}$ \\
\hline
\end{tabular}

$241 \quad{ }^{1}$ Scenario where everyone has the same smoking prevalence as the least deprived quintile; ${ }^{2}$ Scenario

242 where nobody smoked

$243{ }^{\mathrm{a}}$ Calculation: $957=3562-2605 ; 21.9 \%=957 / 4380$

244 *head and neck (oral cavity, salivary glands, pharynx, nasopharynx, larynx, nasal cavity and middle

245 ear, accessory sinuses), oesophagus, stomach, colorectal, liver, pancreas, lung, cervix uteri, kidney,

246 bladder, small intestine, anal, gallbladder, vulva, vagina, corpus uteri, penis, Hodgkin Lymphoma and

247 cancer of unknown primary

$248 * *$ oral cavity, pharynx, nasopharynx, larynx, oesophagus, stomach, colorectal, liver, pancreas, lung,

249 cervix uteri, kidney, bladder, ovarian (mucinous) and leukaemia (acute myeloid)

250

251 Sensitivity Analysis

252 The PAFs estimated from smoking prevalence by IMD all domains were similar to the PAFs

253 estimated from smoking prevalence by equivalised household income. For females, the PAFs

254 increased from $7.9 \%$ in the least deprived quintile to $18.4 \%$ in the most deprived. For males, 
medRxiv preprint doi: https://doi.org/10.1101/2022.02.11.22270853; this version posted February 13, 2022. The copyright holder for this preprint (which was not certified by peer review) is the author/funder, who has granted medRxiv a license to display the preprint in perpetuity. All rights reserved. No reuse allowed without permission.

255 the PAFs increased from $12.1 \%$ in the least deprived to $24.3 \%$ in the most deprived (see

256 Supplementary Material F). 


\section{Discussion}

\section{Interpretation of main findings}

We observed a strong deprivation gradient for the proportion of cancer cases attributable to smoking in England, which reflects the clear and longstanding socio-economic inequality observed for smoking prevalence in England. ${ }^{9,16}$

Smoking is a key driver of socio-economic inequality in cancer incidence in England. If everyone had the same smoking prevalence as the least deprived quintile $20 \%$ (5,504 cases every year) of deprivation-associated cancer cases between 2013 and 2017 could have been prevented. If no one in England had smoked, $61 \%$ (16,544 cases every year) of deprivationassociated cases could have been prevented, indicating that smoking explained the majority of the observed deprivation gap in cancer incidence in England between 2013 and 2017.

Though the majority of the observed deprivation gap in cancer incidence can be explained by smoking for both sexes, other risk factors are probably contributing to the remainder of the gap. Obesity (body mass index [BMI] 30+) is positively associated with deprivation for adults in England, ${ }^{10}$ as well as being related to 8 cancer types that are also related to deprivation. ${ }^{3,8}$ Routine and manual workers may have higher risk of exposure to occupational risk factors (e.g. asbestos, silica, aromatic amines) that are related to cancers of the lung, head and neck and bladder. ${ }^{17,18,19,20}$ Prevalence of the human papillomavirus (HPV) infection and helicobacter pylori infection are positively associated with deprivation in the UK, and are linked to numerous cancers that are more common in deprived areas. ${ }^{8,21,22}$

Other research has addressed the hypothetical removal of socio-economic inequality in risk factor exposure on subsequent cancer incidence or mortality, however direct comparisons are precluded by methodological differences (e.g. measure of deprivation, RRs, outcome measures). A French study estimated that $43.4 \%$ and $27.5 \%$ of deprivation-associated cancer 
cases for smoking-related cancer types could have been prevented if everyone smoked like

307 the least deprived, in females and males respectively. ${ }^{11}$ In Australia it was estimated that $4 \%$

of all cancer cases could have been prevented if smoking, overweight and obesity and

physical activity prevalence matched the least deprived across all deprivation quintiles. ${ }^{12}$

310 Smoking accounted for the vast majority of these deprivation-associated cases. A UK team

311 showed that $30 \%$ of lung and laryngeal cancer deaths in men, and $23 \%$ of those in women,

312 could be prevented if everyone smoked like those with tertiary education. ${ }^{23}$

\section{$313 \quad$ Policy Implications}

314 The UK government's prevention green paper recently set the aim of England becoming 315 smoke free by 2030 , defined as smoking prevalence below $5 \% .{ }^{24}$ Successful UK public health initiatives have contributed to overall smoking prevalence declining over time, ${ }^{25}$ but

317 smoking inequalities have widened. ${ }^{9,16}$ The Marmot review of 2010 argued that action is 318 needed across the social gradient 'with a scale and intensity that is proportionate to the level 319 of disadvantage' ${ }^{26}$ To incorporate this, action is needed at both a national and local level.

320 Fiscal measures provide a national cost-effective approach to help target and reduce smoking prevalence, particularly for future generations, whilst also increasing government revenues. ${ }^{27}$ And fiscal measures may also be effective for more deprived smokers where price is more of a potential barrier to consumption. ${ }^{28,29}$ A study modelling the impact of a $10 \%$ increase per annum in the price of cigarettes in England and Wales projected a $74 \%$ and $86 \%$ reduction in the socio-economic gap in lung cancer incidence by 2050, in females and males, respectively. ${ }^{30}$

327 Local level support can aid smoking cessation for current smokers, particularly for those from

328 the most deprived communities. Smokers from deprived backgrounds are subject to barriers

329 (e.g. lack of social support, high nicotine dependence) that makes it difficult for them to 
330 quit. ${ }^{31,32,33}$ Local Stop Smoking Services provide multi-faceted smoking cessation support

331 within communities that can engage with smokers from deprived communities. ${ }^{33,34}$ However,

332 these services are increasingly threatened due to central funding cuts, making it difficult for

333 them provide support locally across the country. Reversing of these cuts would likely help

334 tackle smoking inequalities and prove cost-effective, by reducing smoking-related ill-health

335 that negatively impacts on the National Health Service and productivity. ${ }^{35,36}$

\section{Strengths and Limitations}

We provide a unique quantification of the relationship between socio-economic deprivation, smoking and subsequent cancer incidence in England. Modelling like this may help inform and reinforce policy to prevent smoking-related cancer and improve health more generally in deprived populations. The analysis used high quality cancer incidence and smoking prevalence data, which was averaged over 5 years to reduce the risk of spurious results as a consequence of any year-on-year fluctuation.

This analysis is not without limitations. The same RRs for current and ex-smoking prevalence were applied across all deprivation quintiles. This may reduce the accuracy of the point estimates if the risk associated with those broad definitions varies by deprivation quintile. For example, more deprived smokers may smoke more heavily and start smoking younger. ${ }^{37,38}$

347 They are also more likely to have multiple cancer risk factors, ${ }^{39}$ including those which combine synergistically with smoking to raise cancer risk, such as alcohol, ${ }^{40,41}$ obesity $^{42,43}$ and 349 occupational exposures. ${ }^{44,45}$ However, the net effect of this is likely to be underestimation of 350 the deprivation gap in smoking PAFs.

351 These calculations can only be considered estimates because of the PAF methodology used, 352 which is an indirect and relatively simple method that is subject to some uncertainty around 353 point estimates. We used a 10-year latency period, in line with Parkin et al.'s methodology, ${ }^{13}$ 
and this may under-represent the true lag time between smoking exposure and subsequent

356 deprivation group from exposure through to recording of cancer incidence. The cancer

357 incidence data uses highly granular area-level rather than individual-level deprivation,

358 meaning these findings may be subject to ecological fallacy.

\section{Conclusion}

360 Smoking is an important driver of cancer incidence inequalities in England. Efforts to reduce smoking prevalence should focus on minimising smoking inequalities. More research is required to better understand and overcome the complex barriers that smokers from deprived populations face in order to enhance smoking cessation interventions. 


\section{Additional Information}

\section{Acknowledgements}

We acknowledge the work of the England cancer registry, as without their work there would be no incidence data. This work uses data provided by patients and collected by the NHS as part of their care and support. We also acknowledge the work of NHS Digital of the Health Survey for England team at the Health and Social Survey Research group at the Department of Epidemiology at University College London with NatCen Social Research for their smoking prevalence data. Their data provides detailed and reliable breakdowns across a range of different metrics and over many years, that helped enable this research to take place.

\section{Authors' contributions}

NP carried out the main analysis and wrote the manuscript. KB, IS and JS provided advice and support on the analysis and manuscript. CD provided support by checking methods and data. YK accessed the data and helped prep part of it.

\section{Ethics approval and consent to participate}

Data was de-identified, obtained from either Public Health England via the Office for Data Release or from a publicly available source (UK Data Service). Therefore, no ethical approval was necessary as part of accessing these data.

\section{Data availability}

The cancer incidence data analysed during the current study are available from the National Cancer Registration and Analysis Service (part of Public Health England), on request through the Office for Data Release but restrictions apply to the availability of these data, which were used under license for the current study, and so are not publicly available.

The population and smoking prevalence data are publicly available.

\section{Competing interests}

We, the authors, declare we have no conflicts of interest.

\section{Funding information}

The authors received no specific funding for this work. 
${ }^{1}$ Brown, K.F., Rumgay, H., Dunlop, C. et al. The fraction of cancer attributable to modifiable risk factors in England, Wales, Scotland, Northern Ireland and the United Kingdom in 2015. Br J Cancer 118: 1130-1141 (2020), DOI: 10.1038/s41416-018-0029-6

${ }^{2}$ Global Health Data Exchange. Global Burden of Disease (GBD) Results Tool. Available from

http://ghdx.healthdata.org/gbd-results-tool. Accessed February 2021

${ }^{3}$ Cancer Research UK (2020). Incidence of common cancers by deprivation. Available from https://www.cancerresearchuk.org/health-professional/cancer-statistics/incidence/common-cancerscompared\#heading-Five. Accessed February 2021

${ }^{4}$ Information Services Division Scotland. Cancer Statistics. Available from https://www.isdscotland.org/HealthTopics/Cancer/Cancer-Statistics/All-Types-of-Cancer/. Accessed February 2021

${ }^{5}$ Welsh Cancer Intelligence and Surveillance Unit. Cancer incidence in Wales 2002-2018. Available from https://phw.nhs.wales/services-and-teams/welsh-cancer-intelligence-and-surveillance-unit-wcisu/cancerincidence-in-wales-2002-2018/. Accessed February 2021

${ }^{6}$ Northern Ireland Cancer Registry. Cancer information. Available from https://www.qub.ac.uk/researchcentres/nicr/CancerInformation/official-statistics/. Accessed February 2021

${ }^{7}$ Cancer Research UK. Cancer in the UK 2020: Socio-economic deprivation.

https://www.cancerresearchuk.org/sites/default/files/cancer inequalities in the uk.pdf

${ }^{8}$ International Agency for Research on Cancer (2021). Agents classified by the IARC Monographs, Volumes 1129. Available from https://monographs.iarc.who.int/agents-classified-by-the-iarc/. Accessed February 2021

${ }^{9}$ Office for National Statistics. Adult smoking habits in the UK: 2019. Available from

https://www.ons.gov.uk/peoplepopulationandcommunity/healthandsocialcare/healthandlifeexpectancies/bulletin s/adultsmokinghabitsingreatbritain/2019\#characteristics-of-current-cigarette-smokers-in-the-uk. Accessed February 2021

${ }^{10}$ NHS Digital. Health Survey for England 2019. Available from https://digital.nhs.uk/data-andinformation/publications/statistical/health-survey-for-england/2019. Accessed February 2021

${ }^{11}$ Menvielle, G., Kulhánová, I., Bryere, J. et al. Tobacco-attributable burden of cancer according to socioeconomic position in France. Int J Cancer 143: 478-485 (2018), DOI: 10.1002/ijc.31328

${ }^{12}$ Wilson LF, Green AC, Jordan SJ et al. The proportion of cancers attributable to social deprivation: A population-based analysis of Australian health data. Cancer Epi 67: 101742 (2020),

DOI: $10.1016 /$ j.canep.2020.101742

${ }^{13}$ Parkin, D.M. The fraction of cancer attributable to lifestyle and environmental factors in the UK in 2010 . Br J Cancer, 105(2), pp.S77-S81 (2011), DOI: 10.1038/bjc.2011.489

${ }^{14}$ Eurostat. Revision of the European Standard Population. Available from https://ec.europa.eu/eurostat/documents/3859598/5926869/KS-RA-13-028-EN.PDF/e713fa79-1add-44e8-b23d5e8fa09b3f8f. Accessed February 2021

${ }^{15}$ Cancer Research UK and National Cancer Intelligence Network. Cancer by deprivation in England: Incidence, 1996-2010, Mortality, 1997-2011 (2014), London: NCIN. Available from http://www.ncin.org.uk/about_ncin/cancer_by_deprivation_in_england. Accessed February 2021

${ }^{16}$ Cancer Intelligence Team, Cancer Research UK (2019). Smoking prevalence trends by occupation group in Health Survey for England.

https://www.cancerresearchuk.org/sites/default/files/smoking_prevalence_trends_occupation_final_2020.pdf

${ }^{17}$ McCormack, V., Peto, J., Byrnes, G. et al. Estimate the asbestos-related lung cancer burden from mesothelioma mortality. Br J Cancer 106(3): 575-84 (2012), DOI: 10.1038/bjc.2011.563

${ }^{18}$ Poinen-Rughooputh, S., Rughooputh, M., Guo, Y., et al. Occupational exposure to silica dust and risk of lung cancer: an updated meta-analysis of epidemiological studies. BMC Pub Health 16(1): 1-17 (2016), DOI: $\frac{10.1186 / \mathrm{s} 12889-016-3791-5}{19}$

${ }^{19}$ Brown, T., Darnton, A., Fortunato, L., et al. Occupational cancer in Britain. Respiratory cancer sites: larynx, lung and mesothelioma. Br J Cancer 107: S56-70 (2012), DOI: 10.1038/bjc.2012.119

${ }^{20}$ Brown, T., Slack, R., Rushton, L. British Occupational Cancer Burden Study Group. Occupational cancer in Britain. Urinary tract cancers: bladder and kidney. Br J Cancer 19: S76-84 (2012), DOI: 10.1038/bjc.2012.121

${ }^{21}$ Tanton, C., Soldan, K., Beddows, S. et al. High-risk human papillomavirus (HPV) infection and cervical cancer prevention in Britain: Evidence of differential uptake of interventions from a probability survey. Cancer Epi \& Prev Bio 24(5): 842-53 (2015), DOI: 10.1158/1055-9965

${ }^{22}$ Khalifa, M.M., Sharaf, R.R., Aziz, R.K. Helicobacter pylori: a poor man's gut pathogen? Gut Path 2(1): 1-2 (2010), DOI: 10.1186/1757-4749-2-2

${ }^{23}$ Kulik, M.C., Hoffmann, R., Judge, K. et al. Smoking and the potential for reduction of inequalities in mortality in Europe. Eur J Epi 28(12): 959-71 (2013), DOI: 10.1007/s10654-013-9860-5 
${ }^{24}$ Department of Health and Social Care (2019). Advancing our health: prevention in the 2020s - consultation document. Available from https://www.gov.uk/government/consultations/advancing-our-health-preventionin-the-2020s/advancing-our-health-prevention-in-the-2020s-consultation-document. Accessed February 2021 ${ }^{25}$ Office for National Statistics. Adult smoking habits in Great Britain. Available from https://www.ons.gov.uk/peoplepopulationandcommunity/healthandsocialcare/drugusealcoholandsmoking/datase ts/adultsmokinghabitsingreatbritain

${ }^{26}$ Marmot, M., Goldblatt, P., Allen, J. et al. Fair society, healthy lives. Pub Health 126: S4-10 (2012), DOI: https://doi.org/10.1016/j.puhe.2012.05.014

${ }^{27}$ Chaloupka, F.J., Straif, K., Leon, M. E. Effectiveness of tax and price policies in tobacco control. Tob Control 20(3): 235-238 (2011), DOI: http://dx.doi.org/10.1136/tc.2010.039982

${ }^{28}$ Townsend, J.L., Roderick, P. \& Cooper, J. Cigarette smoking by socioeconomic group, sex, and age: effects of price, income, and health publicity. Br Med J 309: 923-926 (1994), DOI:

https://doi.org/10.1136/bmj.309.6959.923

${ }^{29}$ Farrelly, M.C., Bray, J.W., Pechacek, T. et al. The response by adults to increases in cigarette prices by sociodemographic characteristics. S Econ J, 68(1): 156-165 (2001), DOI: https://doi.org/10.2307/1061518

${ }^{30}$ Soerjomataram, I., Barendregt, J.J., Gartner, C. et al. Reducing inequalities in lung cancer incidence through smoking policies. Lung C 73(3): 286-273 (2011), DOI: https://doi.org/10.1016/j.lungcan.2011.01.009

${ }^{31}$ Brose, L.S. \& McEwen, A. Neighbourhood deprivation and outcomes of stop smoking support - an

observational study. PLoS One 11(1): e0148194 (2016), DOI: 10.1371/journal.pone.0148194

${ }^{32}$ Hiscok, R., Dobbie, F. \& Bauld, L. Smoking cessation and socioeconomic status: an update of existing evidence from a national evaluation of English Stop Smoking Services. BioMed R Int 2015 (2015), DOI: https://doi.org/10.1155/2015/274056

${ }^{33}$ National Centre for Smoking Cessation and Training (2013). Stop Smoking Services and Health Inequalities. Available from https://www.ncsct.co.uk/usr/pub/NCSCT briefing effect of SSS on health inequalities.pdf. Accessed February 2021

${ }^{34}$ Smith CE, Hill SE, Amos A. Impact of specialist and primary care stop smoking support on socio $\square$ economic inequalities in cessation in the United Kingdom: a systematic review and national equity analysis.

Addiction.Jan;115(1):34-46 (2020), DOI: https://doi.org/10.1111/add.14760

${ }^{35}$ Allender, S., Balakrishnan, R., Scarborough, P. et al. The burden of smoking-related ill health in the UK. Tob Ctrl 18(4): 262-267 (2009), DOI: $\underline{10.1136 / t c .2008 .026294}$

${ }^{36}$ Baker, C.L., Flores, N.M., Zou, K.H. et al. Benefits of quitting smoking on work productivity and activity impairment in the United States, the European Union and China. Int J Clin Prac 71(1): e12900 (2017), DOI:

10.1111/ijcp.12900

${ }^{37}$ Jarvis, M.J., Wardle, J., Waller, J. et al. Prevalence of hardcore smoking in England, and associated attitudes and beliefs: cross sectional study. BMJ 326(7398): 1061 (2003), DOI:

https://doi.org/10.1136/bmj.326.7398.1061

${ }^{38}$ Belvin, C., Britton, J., Holmes, J. et al. Parental smoking and child poverty in the UK: an analysis of national survey data. BMC Pub Health 15(1): 1-8 (2015), DOI: 10.1186/s12889-015-1797-Z

${ }^{39}$ NHS digital. Health Survey for England 2017. Multiple risk factors. Available from http://healthsurvey.hscic.gov.uk/media/78655/HSE17-MRF-rep.pdf. Accessed February 2021

${ }^{40}$ Hashibe, M., Brennan, P., Chuang, S.C. et al. Interaction between tobacco and alcohol use and the risk of head and neck cancer: pooled analysis in the International Head and Neck Cancer Epidemiology Consortium. C Epi Prev Bio 18(2): 541-550 (2009), DOI: 10.1158/1055-9965.EPI-08-0347

${ }^{41}$ Prabhu, A., Obi, K.O. \& Rubenstein, J.H. The synergistic effects of alcohol and tobacco consumption on the risk of oesophageal squamous cell carcinoma: a meta-analysis. Am J Gastroenterol 109(6): 822-827 (2014), DOI: 10.1038 /ajg.2014.71

${ }^{42}$ Marrero, J.A., Fontana, R.J., Fu, S. et al. Alcohol, tobacco and obesity are synergistic risk factors for hepatocellular carcinoma. J Hepatology 42(2): 218-224 (2005), DOI: https://doi.org/10.1016/j.jhep.2004.10.005

${ }^{43}$ Roos, E.T., Lallukka, T., Lahelma, E. et al. Joint associations between smoking and obesity as determinants of premature mortality among midlife employees. Eur J Public Health 27(1): 135-139 (2017), DOI:

10.1093/eurpub/ckw111

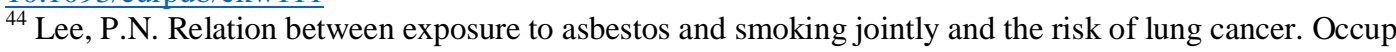
Environ Med 58(3): 145-153 (2001), DOI: 10.1136/oem.58.3.145

${ }^{45}$ Hertz-Picciotto, I., Smith, A.H., Holtzman, D. et al. Synergism between occupational arsenic exposure and smoking in the induction of lung cancer. Epidemiology 3(1): 23-31 (1992), DOI: 10.1097/00001648-

$\underline{199201000-00006}$ 

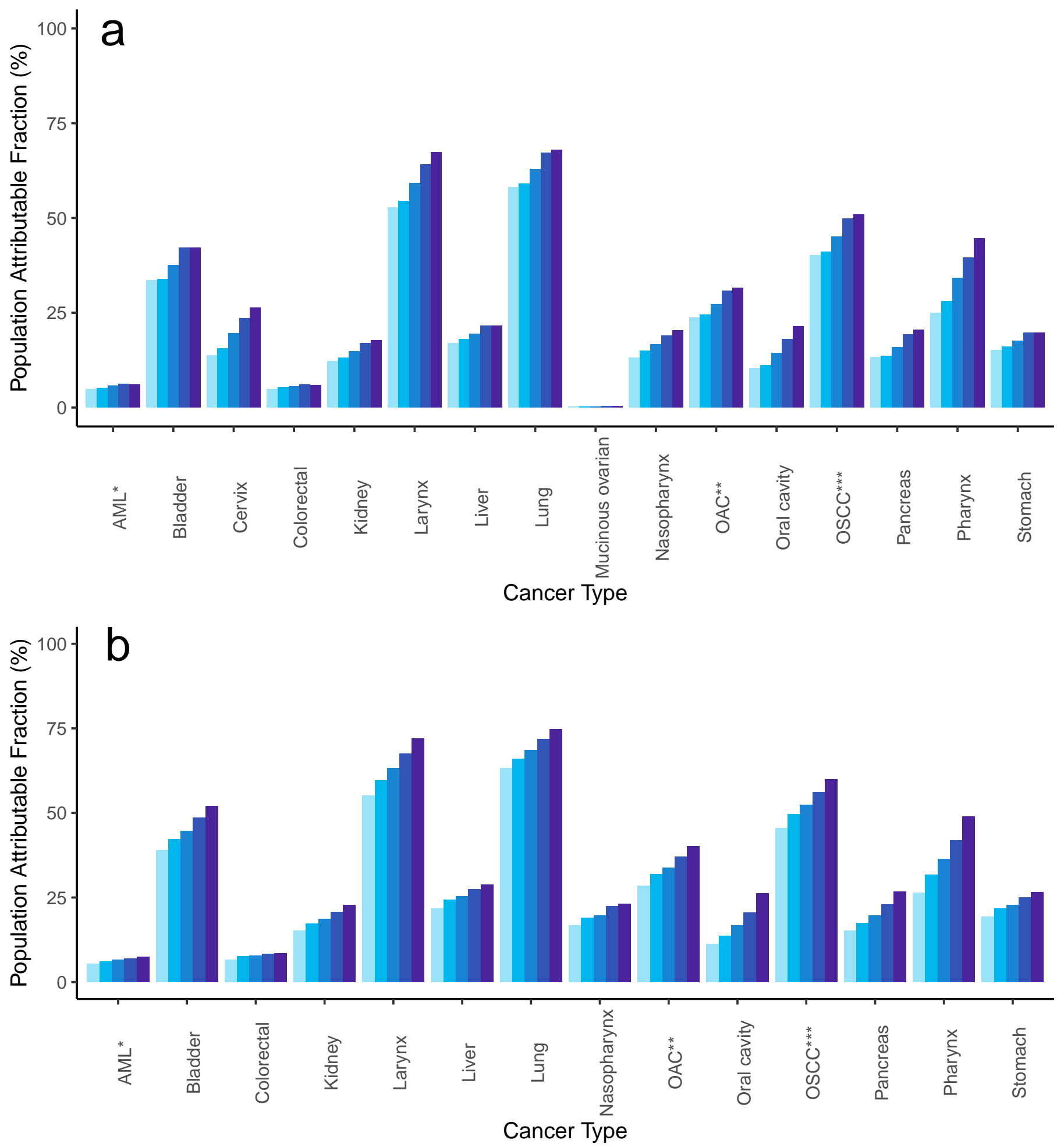

Deprivation Quintile: 1 (least) 2

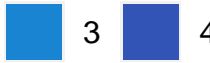
4 (most) 

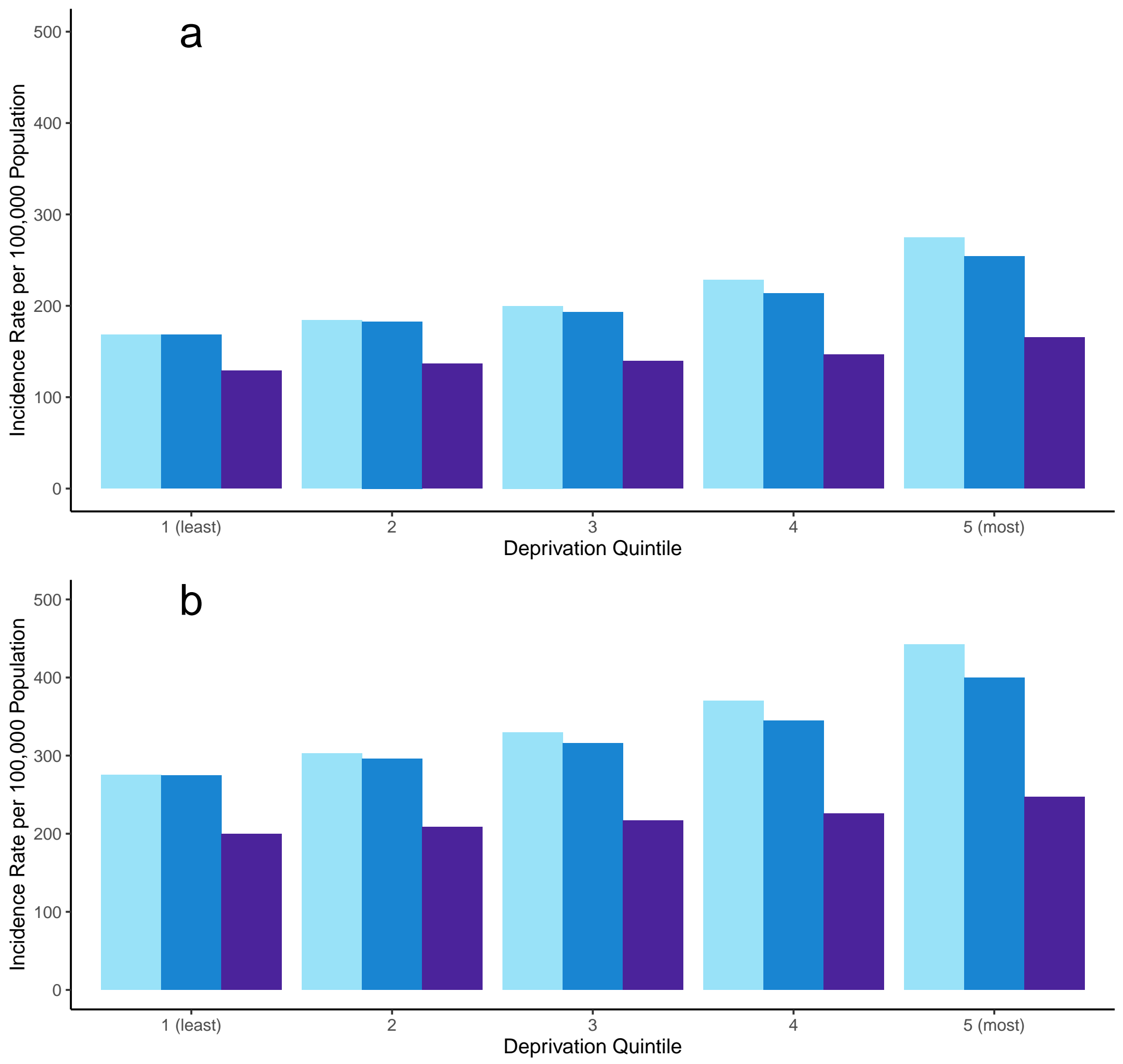

Scenario: Observed $\quad$ Scenario 1: everyone smoked like least deprived $\quad$ Scenario 2: nobody smoked 